ISSN (e)-2347-176x ISSN (p) 2455-0450

crossrefDOI: https://dx.doi.org/10.18535/jmscr/v7i1.100

Journal Of Medical Science And Clinical Research

IGM Publication

An Official Publication of IGM Publication

\title{
Correlation of intra ocular pressure, measured by 2 different tonometers
}

Authors

Prasanthi $\mathbf{M}^{1}$, Suganya $\mathbf{E}^{2 *}$, Ravikumar $\mathbf{R}^{3}$

${ }^{1}$ Assistant Professor, Dept. of Ophthalmology, TMCH, Chennai, India

${ }^{2}$ Assistant Professor, Dept. of Community Medicine, TMCH, Chennai, India

${ }^{3}$ Professor and Head, Dept. of Ophthalmology, TMCH, Chennai, India

*Corresponding Author

Dr Suganya E

Assistant Professor, Dept. of Community Medicine, TMCH, Chennai, India

Phone: 9894281794; Email: drsuganyae@gmail.com

\begin{abstract}
Background: Intraocular pressure (IOP) being an modifiable risk factor of glaucoma, has to be assessed earlier for successful identification d and treatment of glaucoma.

Objectives:

1. To assess the Intra ocular pressure (IOP) using GAT and Schiotz tonometer

2. To compare and correlate the GAT and Schiotz tonometer in measuring the IOP
\end{abstract}

Materials and Methods: Cross-sectional study conducted in Ophthalmology department of SSSIHMS, Andhra Pradesh for a period of 2 months. 112 study participants were included in the study and their IOP was assessed using GAT and Schiotz tonometers and the readings were compared. Statistical analysis was done using Pearson correlation and Paired t test.

Results: The mean age of the participants was $53.20 \pm 13.03$ years. Most of them are males $66(58.9 \%)$, illiterates 50(44.7\%) and they belonged to Class I socio-economic status 49(43.7\%). The average intra ocular pressure was high in females than males measured using both the Goldmann applanation tonometer (GAT) and Schiotz tonometers. The difference in right eye IOP was higher than Left eye. Pearson correlation showed a moderate positive correlation between the 2 tonometric assessment, having $r$ value of 0.577 and it was statistically significant. Paired t test inferred that the difference in the IOP readings assessed by 2 tonometers are not significant.

Conclusion: The insignificant difference between the IOP measured using 2 tonometers, proves that Schiotz tonometer is comparable with gold standard GAT in assessing the IOP, hence Schiotztonometric measurements could be considered as a screening procedure for Glaucoma.

Keywords: Schiotz tonometer, GAT, Glaucoma.

\section{Introduction}

"GLAUCOMA" is the leading cause of permanent blindness worldwide. Intra Ocular Pressure (IOP) is an important modifiable risk factor in the treatment of glaucoma. The assessment of IOP, plays a significant role in screening for the detection and treating of patients with glaucoma, because, early, successful treatment of elevated IOP can prevent optic nerve damage and blindness. Normal IOP values range from 10 to $21 \mathrm{~mm} \mathrm{Hg}(15.5 \mathrm{~mm} \mathrm{Hg}+/-$ $2 \mathrm{SD})$. Tonometry is the measure of intraocular 
pressure, which is measured by an instrument called Tonometers ${ }^{1,2}$ Applanation Tonometry is the method of measuring IOP with instruments that indent or flatten the corneal apex. The Goldmann applanation tonometer (GAT) is regarded as the Gold standard for measuring IOP, however it has known limitations like influence of Central Corneal Thickness (CCT) and corneal curvature, necessity to support the upper lid during measurement, use of topical anaesthesia and fluorescein staining of the tear film. ${ }^{3}$ Schiotz tonometer is a prototype of indentation tonometer. It is portable, sturdy, relatively inexpensive and easy to operate. ${ }^{4}$

Among clinical instruments presently available GAT, may provide the most valid estimate of intraocular pressure in humans. Examination with this tonometer offers a promising method of collecting descriptive data on the frequency distribution of intraocular pressure. Accordingly, it is important to compare the field performance of Goldmann applanation tonometry with Schiotz indentation tonometry, since the Schiotz instrument has been used in most population studies. ${ }^{5}$

This study aims at comparing the Schiotz tonometer against the gold standard Goldmann applanation tonometer (GAT) in measuring the IOP and to assess the correlation between them.

\section{Objectives}

1. To assess the Intra ocular pressure (IOP) using GAT and Schiotz tonometer

2. To compare and correlate the GAT and Schiotz tonometer in measuring the IOP

\section{Materials and Methods}

This study is a part of DNB ophthalmology thesis. It is a cross-sectional study, conducted in outpatient section of Department of Ophthalmology, Sri Sathya Sai Institute of Higher Medical Sciences (SSSIHMS) Prasanthigram, Anantapur district, Andhra Pradesh, India. Only those patients reported to the outpatient department from April 2011 to April 2012 were included in the study. The study population included where those, patients presenting to the eye clinic of SSSIHMS, aged above 15 years, without any active intraocular inflammation having normal intraocular pressure, without any systemic illness.

\section{Results}

Out of 112 study participants, maximum number of participants were aged $>50$ years $(57.2 \%)$, the mean age of the participants was $53.20 \pm 13.03$ and most of them were males $66(58.9 \%)$. It was also noted that nearly half of them were Illiterate $(44.7 \%)$ and only less than $5 \%$ of them were graduated .According to modified kuppusamy scale classification, most $(43.7 \%)$ of them belonged to Class I socio-economic status [Table 1]

The average intra ocular pressure was high in females than males measured using both the Goldmann applanation tonometer (GAT) and Schiotz tonometer, however the there was a difference in mean IOP measurement using the 2 tonometers and the average IOP among females was high with GAT(15.14 $\mathrm{mm}$ of $\mathrm{Hg}$ ) than Schiotz (14.99 $\mathrm{mm}$ of $\mathrm{Hg}$ ) tonometric assessment [Figure 1] There was a difference in IOP measurements between the right and left eye measured with both the tonometers. The difference in right eye IOP was higher assessed using GAT $(15.24 \pm 3.00 \mathrm{~mm}$ of $\mathrm{Hg}$ ) and $\operatorname{Schiotz}(14.04 \pm 3.24 \mathrm{~mm}$ of $\mathrm{Hg}$ ) tonometers, comparing the left eye IOP using GAT and Schiotz which was $14.90 \pm 3.17 \mathrm{~mm}$ of $\mathrm{Hg}$ and $14.58 \pm 3.54$ $\mathrm{mm}$ of $\mathrm{Hg}$ respectively.[Table 2] Pearson correlation was done to identify the relationship between the IOP measurements using GAT and Schiotztonometric assessment, which obtained the $\mathrm{r}$ value of 0.577 , indicating a moderate positive correlation and it was statistically significant, having a $\mathrm{p}$ value of $<0.05$. Paired t test was done to determine whether the difference in IOP measured using 2 types of tonometers are significant, it was found that, the differences are not significant hence comparable, having a p value of 1.0056 [Table 3] 
Table 1: Distribution of participants based on socio-demographic variables $(n=112)$

\begin{tabular}{|l|c|}
\hline PARAMETERS & FREQUENCY (\%) \\
\hline AGE (in years) & $3(2.6 \%)$ \\
$<30$ & $45(40.2 \%)$ \\
$30-50$ & $64(57.2 \%)$ \\
$>50$ & \\
\hline Mean \pm SD: $53.20 \pm 13.03$ & \\
\hline SEX & $66(58.9 \%)$ \\
Males & $46(41.1 \%)$ \\
Females & \\
\hline EDUCATION & $50(44.7 \%)$ \\
Illiterate & $32(28.6 \%)$ \\
Primary/Secondary & $25(22.3 \%)$ \\
High school/Higher Sec & $5(4.5 \%)$ \\
Graduates and above & \\
\hline Socio-economic status & $49(43.7 \%)$ \\
Class I & $21(18.7 \%)$ \\
Class II & $17(15.1 \%)$ \\
Class III & $25(22.3 \%)$ \\
Class IV &
\end{tabular}

Table 2: Comparison of IOP measurements between Right Eye and Left Eye using GAT and SCHIOTZ

\begin{tabular}{|c|c|c|c|c|}
\hline \multirow{2}{*}{\multicolumn{2}{c|}{ EYE }} & \multicolumn{4}{|c|}{ Measurements in mm of Hg (Mean \pm SD) } \\
\cline { 2 - 5 } & Measurement1 & Measurement2 & Measurement3 & Average \\
\hline Right eye & & & & \\
\hline$\square \quad$ GAT & $14.99 \pm 3.12$ & $15.21 \pm 2.98$ & $15.52 \pm 3.06$ & $15.24 \pm 3.00$ \\
\hline$\square \quad$ SCHIOTZ & $14.29 \pm 3.44$ & $14.06 \pm 3.24$ & $13.88 \pm 3.33$ & $14.04 \pm 3.24$ \\
\hline Left eye & & & & $14.90 \pm 3.17$ \\
\hline$\square \quad$ GAT & $14.68 \pm 3.29$ & $14.95 \pm 3.19$ & $15.06 \pm 3.27$ & $14.58 \pm 3.54$ \\
\hline$\square \quad$ SCHIOTZ & $14.70 \pm 3.63$ & $14.48 \pm 3.82$ & $14.53 \pm 3.65$ & \\
\hline
\end{tabular}

Table 3: Correlation and paired t test interpretation

\begin{tabular}{|l|c|c|}
\hline \multirow{2}{*}{ SCHIOTZ vs GAT } & Pearson correlation & Significance \\
& 0.577 & $<0.0001$ \\
\cline { 2 - 3 } & Paired test & Significance \\
& 1.066 & 1.0056 \\
\hline
\end{tabular}

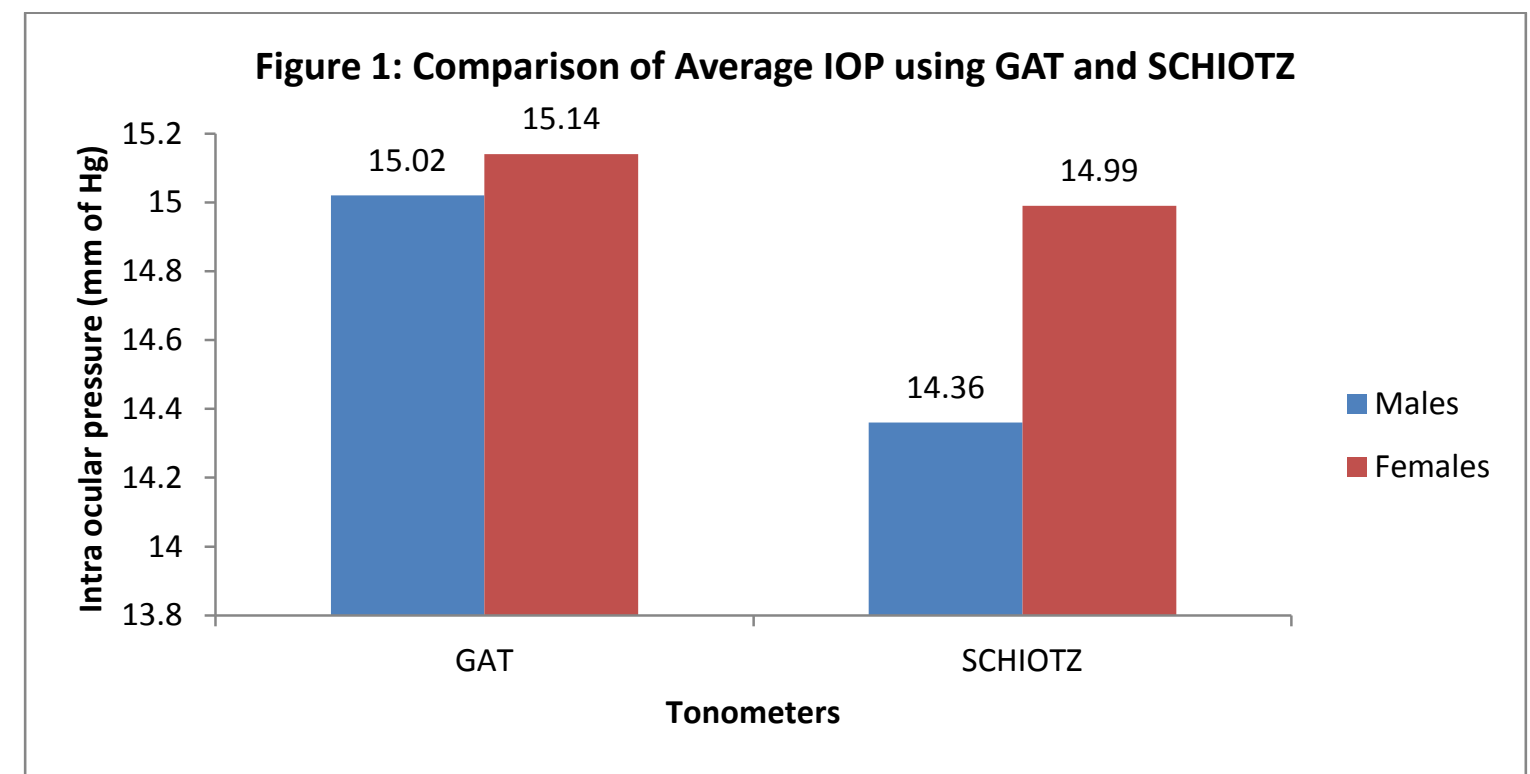




\section{Discussion}

Intra ocular pressure being an important risk factor for glaucoma, has to be determined accurately, in order to diagnose at an earlier stage. The mean IOP measured using the gold standard tonometric assessment was $15.24 \pm 3.00$ in Right eye and $14.90 \pm 3.17$ in left eye respectively. In a study conducted by Schreiber W etal ${ }^{6}$ the mean IOP(GAT) was $13.2+/-3.0 \mathrm{mmHg}$, which was less compared to our present study findings

Jonathan SP, in his study, mentioned that, for either gender, the absolute mean level of IOP remains little altered from childhood into and throughout adulthood. However the physiological basis for these observations remains obscure. In this study also the intra ocular pressures in female subjects were found to be more than males. The above study is in perfect agreement with our study. ${ }^{7}$ In a study done by Vinayak et al, 248 eyes of 60 healthy subjects, 31 patients with POAG, 16 patients with PACG \& 17 patients with OHT underwent IOP evaluation with NCT, GAT \& Schiotz tonometer). Finally they concluded that IOP as recorded by the three tonometers was not statistically significantly different from each other, so any of these tonometers can be safely used for routine glaucoma workup. This study was in perfect agreement with our study. ${ }^{8}$

According to the study conducted by Ohana $\mathrm{O}$ etal ${ }^{9}$ it was found that GAT and Schiotz tonometry had a statistically significant difference, with a mean difference of $1.15 \pm 3.04 \mathrm{mmHg}(P=0.046$, Wilcoxon signed test). This finding was contrary to our present finding which shows that there is no significant difference between GAT and Schiotz in determining the IOP.

Schiotztomoter often generated a relatively high reading of IOP and in that case the patient must be assessed using GAT, before diagnosing them to have high intra ocular pressure. ${ }^{10}$ In our present study, Schiotztonometric IOP reading is less than the IOP reading obtained by using GAT. The mean IOP measured in Right and Left eye using GAT (15.24 $\pm 3.00 \mathrm{~mm}$ of $\mathrm{Hg}$ and $14.90 \pm 3.17 \mathrm{~mm}$ of $\mathrm{Hg}$ ) and schiotz in Right and left eye are 14.04 $\pm 3.24 \mathrm{~mm}$ of $\mathrm{Hg}$ and $14.58 \pm 3.54 \mathrm{~mm}$ of $\mathrm{Hg}$ respectively. This study finding was in agreement with the previous study conducted by Armalayetal $^{11}$ which says, Significant difference in estimates of intraocular pressure of the same eye, obtained by the two methods, was shown to occur with an undesirably high frequency in the clinically important range of intraocular pressure.

\section{Conclusion}

Glaucoma being an eye threatening condition, has to be identified earlier. GAT, is the gold standard assessment tool for IOP measurement, however an alternate method has to be available to overcome its limitation.

Present study, infers that the IOP difference measured using GAT and Schiotz is insignificant, which concludes that Schiotz can also be used as an standard IOP assessment instrument.

\section{Acknowledgement}

We would like to sincerely thank the participants of our study, for their interest and co-operation.

\section{References}

1. American Academy of Ophthalmology, BCSC. Section 10. Glaucoma. 2009-10.

2. Gordon MA, Beiser JA, Brandt JA, et al. The Ocular Hypertension treatment Study: baseline factors that predict the onset of primary open-angle glaucoma. Arch Ophthalmol. 2002; 120(6):714-720.

3. Frenkel REP, Hong YJ, Shin DH. Comparison of the Tono-Pen to the Goldmann applanation tonometer. Arch Ophthalmol1988,106: 750-53.

4. Becker-schaffers. Diagnosis and therapy of glaucomas , 8th edition.

5. Schwartz JT, Dellosso GG. Comparison of Goldmann and Schiotz Tonometry in a Community. Arch Ophthalmol 1966;75 (6):788-795

6. Schreiber $\mathrm{W}$ etal. A comparison of rebound tonometry (ICare) with TonoPenXL and 
Goldmann applanation tonometry, ophtahlmology 2007 Apr;104(4):299-304.

7. Jonathan SP. Evidence that a gender difference is present from childhood. Ophthalmic and physiological optics. Volume 20, Issue 2, 15 March 2000, Pages 131-136

8. Vinayak Bhatia, Harsh Kumar. Comparison of the Goldmann-applanation, Schiotz impression \&noncontact tonometers in different glaucoma patients \& the effect of central corneal thickness. 10th EGS congress, Copenhagen. JUNE 17-22,2012.

9. Ohana O, Varssano D, Shemesh G. Comparison of intraocular pressure measurements using Goldmann tonometer, I-care pro, Tonopen XL, and Schiotz tonometer in patients after Descemet stripping endothelial keratoplasty. Indian $\mathbf{J}$ Ophthalmol [serial online] 2017 [cited 2018 Dec 5];65:579-83.

10. Stevens $\mathrm{S}$. How to measure intraocular pressure: Schiötz tonometry. Community Eye Health. 2008;21(66):34.

11. Armaly MF, Salamoun SG. Schiotz and Applanation Tonometry. Arch Ophthalmol 1963;70(5):603-609. 